\title{
Synthesis and Characterization of ZnO Nanorod Films on PET for Photocatalytic Disinfection of Water
}

\author{
Luis Sanchez ${ }^{1}$, Lucas Guz ${ }^{2}$, Pilar García ${ }^{1}$, Silvia Ponce ${ }^{3}$, Silvia Goyanes ${ }^{4}$, María Claudia Marchi ${ }^{5}$, \\ Roberto Candal $^{2,5}$, Juan Rodriguez ${ }^{*}, 1$
}

${ }^{1}$ Universidad Nacional de Ingeniería, Lima, Perú

${ }^{2}$ Escuela de Ciencia y Tecnología, Universidad Nacional de San Martín, Argentina

${ }^{3}$ University of Lima, Lima, Perú

${ }^{4}$ Departamento de Física, FCEyN, Universidad de Buenos Aires, IFIBA-CONICET

${ }^{5}$ INQUIMAE, FCEyN, Universidad de Buenos Aires, Argentina

\begin{abstract}
:
$\mathrm{ZnO}$ nanorods ( $\mathrm{ZnO} \mathrm{NRs}$ ) were grown on $\mathrm{ZnO}$ seeded polyethylene tert-phtalate (PET) substrates obtained from recycled soda bottles at low temperatures $\left(90{ }^{\circ} \mathrm{C}\right)$ from $\mathrm{Zn}^{2+}$ precursors in alkaline aqueous solution. The $\mathrm{ZnO}$ seeds were deposited on the PET substrates by spray gel (SG) or dip coating (DC) from a ZnO methanol sol. In the case of SG, the PET substrate was heated at $90{ }^{\circ} \mathrm{C}$ during the spray process. By the other hand the $\mathrm{ZnO}$ seed layers obtained by dip coating were heated at $90{ }^{\circ} \mathrm{C}$ or $130{ }^{\circ} \mathrm{C}$ for 10 minutes among coatings. Before seeding two procedures were made on PET surface for improving seed adhesion: 1) PET surface was mechanically roughened with sand paper 1200. 2) PET surface was chemically treated with a solution of $\mathrm{NaOH}$ in ethanol. The relationship between the microstructure of the $\mathrm{ZnO}$ NRs films as function of the PET surface treatment and the photocatalytic antibacterial activity for $E$. Coli disinfection, was determined through a detailed characterization of the material. The highest photocatalytic antibacterial activity was performed by ZnO NRs films grown on seeds deposited by dip coating with 10 layers, 5 minutes of chemical treatment of PET surface and a thermal treatment at $130^{\circ} \mathrm{C}$ among coatings. With these films the population of viable E. Coli dropped more than seven orders, from $3 \times 10^{8}$ to $10^{1} \mathrm{CFU}$.
\end{abstract}

Keywords: photocatalytic disinfection, nanorods, spray gel, dip coating, $\mathrm{ZnO}$

\section{Introduction}

In recent years, the development of antimicrobial agents that have little or no negative impact on the natural environment has become important. Wastewater is expected to contain high levels of microorganisms and organic compounds; therefore, water disinfection has been an important and essential technology in biological and biochemical industries. Photocatalysis has the potential to provide a low cost and simple solution to the purification of water. The antimicrobial inorganic materials can be used in different forms, such as powders $(1,2)$, or immobilized on a substrate (3-6). Although suspension/slurry reactors are generally found to be more efficient, however, their effective applications are hindered by two serious disadvantages. Firstly, small particles tend to agglomerate into large particles, diminishing catalyst performance. Secondly, the separation and recovery of catalyst is difficult. For those reasons many researchers have been focused on immobilized catalysts. Zinc oxide is an important semiconductor material with a direct wide band gap

*Corresponding author; E-mail address: jrodriguez@uni.edu.pe
$(3.37 \mathrm{eV})$ at room temperature. $\mathrm{ZnO}$ is considered a promising candidate for photocatalysis applications, owing to its band gap value, low toxicity and a rich family of nanostructures (7). Several of such nanostructures, as nanotubes (8), nanowires (9) and nanorods (10), present improved charge transport properties vs. spheroidal nanoparticles, higher surfaceto-volume ratio and stronger contacts with the organic material, resulting in the enhancement of photocatalytic efficiency (11). $\mathrm{ZnO}$ was recently reported as a photocatalytic material to inactivate bacteria Gram negative Escherichia coli $(12,13)$ and Gram positive bacteria such as Lactobacillus Helvetica (14) and Staphylococcus aureus $(15,16)$. $\mathrm{ZnO}$ nanorods ( $\mathrm{ZnO}-$ NRs) present the advantage that they can be grown onto different substrates e.g. glass, quartz, conductive glass, silicon, paper and plastics using wet chemistry such as sol-gel or hydrothermal processes provided the substrate is suitably seeded. Moreover, it has been demonstrated that the presence of seeds is a necessary condition for obtaining arrays of oriented supported $\mathrm{ZnO}$ NRs, otherwise deposits may display diverse structures-e.g. flowers and stars grown from nucleus 
developed in the solution phase $(17,18)$. The use of $\mathrm{ZnO}$ nanoparticles as seeds is an attractive alternative (19). By this way seeds can be deposited on the substrates at moderate temperatures by different methods, such as spray gel (SG), a process that combines the use of sols with spray pyrolysis $(20,21)$, dip coating (DC) or spin coating. In this novel approach the nanoparticles are already synthesized in the sol, and further thermal treatment is needed only for solvent evaporation which makes it suitable to seeded thermo-sensitive substrates, such as flexible organic polymers.

In this work, we present the synthesis by wet chemistry route of $\mathrm{ZnO} \mathrm{NRs}$ on polyethylene terphtalate (PET) substrates, which were previously seeded with $\mathrm{ZnO}$ nanoparticles. Before seeding, to improve seed adhesion, the PET surface was modified by applying the following procedures: 1) PET surface was mechanically roughened with sand paper 1200. 2) PET surface was chemically treated with a solution of $\mathrm{NaOH}$ in ethanol. The relationship between the microstructure of the $\mathrm{ZnO}$ NRs films as function of the PET surface treatment and the photocatalytic antibacterial activity for $E$. Coli disinfection was determined.

\section{Experimental and Methods Materials}

The chemical reactants used as precursors for $\mathrm{ZnO}$ seeds and rods were, respectively, analytical grade zinc acetate $\left[\mathrm{Zn}\left(\mathrm{CH}_{3} \mathrm{COO}\right)_{2} .6 \mathrm{H}_{2} \mathrm{O}\right]$ and zinc nitrate $\left[\mathrm{Zn}\left(\mathrm{NO}_{3}\right)_{2} \cdot 6 \mathrm{H}_{2} \mathrm{O}\right]$ pro analysis (PA) $100 \%$ from Fermont. Sodium hydroxide $(\mathrm{NaOH}) 98 \%$ PA, from EKA Chemicals was used for the nanorods growth solution.

Polyethylene tert-phtalate (PET) obtained from recycled soda bottles were used as the substrate for the growth of $\mathrm{ZnO}$ nanorods. $2.0 \times 1.5 \mathrm{~cm}^{2}$ pieces of PET were cleaned in an ultrasonic bath, first with water and then with ethanol, before depositing the seed layer.

\section{Seed Deposition}

Zinc oxide seed films were first deposited onto the cleaned and pre-treated PET substrate using spray gel (SG) and dip-coating (DC) techniques and were then subsequently used as the substrate to grow $\mathrm{ZnO}$ nanorods.

In a homemade SG device, described in detail elsewhere (22), a medical nebulizer was used as atomizer to produce uniform size droplets which were directed by a nozzle towards the hot substrate $\left(90^{\circ} \mathrm{C}\right)$. The nozzle performed an oscillating movement at constant velocity to scan the whole area of the substrate. Micro-filtered air was used as a carrier gas at a fixed pressure of $1.7 \times 10^{5} \mathrm{~Pa}$ and maintained at a constant flux of $15 \mathrm{~L} / \mathrm{min}$. In both techniques for seed deposition, a nanometric $\mathrm{ZnO}$ sol was used. The methanol based sol of $\mathrm{ZnO}$ nanoparticles was prepared by adding $100 \mathrm{~mL}$ of a $0.030 \mathrm{M} \mathrm{NaOH}$ (EKA chemical, PA) in methanol (Sintorgan, PA) to a 100 $\mathrm{mL}$ of a vigorously stirred $0.020 \mathrm{M}$ solution of $\mathrm{Zn}\left(\mathrm{C}_{2} \mathrm{H}_{3} \mathrm{O}_{2}\right) \cdot 2 \mathrm{H}_{2} \mathrm{O}$ (Riedel-de-Haen, Seelze, Germany) in methanol. This mixture was then heated at $60{ }^{\circ} \mathrm{C}$ under reflux during $2 \mathrm{~h}$, cooled down and stored in a polypropylene bottle. The sol remains clear at least for two weeks. The $\mathrm{ZnO}$ methanol based sol was sprayed on the PET substrates heated at $90{ }^{\circ} \mathrm{C}$. In these experiments 10, 30 and 50 seed layers were successively sprayed. Before seeding PET surface was mechanically roughened with sand paper 1200 , for improving seed adhesion. In the case of seed deposited by dip-coating technique a different approach was implemented for improving seed adhesion. PET substrates were immersed in 0.25 or 2.5 Methanol $\mathrm{NaOH}$ solutions for 2 or 5 minutes at $55{ }^{\circ} \mathrm{C}$. After treatment the substrates were washed with water, dried, dipped in the $\mathrm{ZnO}$ sol for 1 minute and withdrawn at 5 $\mathrm{mm} / \mathrm{min}$. After drying the films at room temperature in air for $5 \mathrm{~min}$, they were thermally treated at $90{ }^{\circ} \mathrm{C}$ and $130{ }^{\circ} \mathrm{C}$ in an oven for $10 \mathrm{~min}$. To obtain a thicker and more uniform seed layer, the overall process, dip coating and the subsequent thermal treatment, was performed five and ten times.

\section{Growth of ZnO NRs Films}

The solution used for the growth of the ZnO NRs was prepared as follows: equal volumes of $\mathrm{Zn}\left(\mathrm{NO}_{3}\right)_{2} .6 \mathrm{H}_{2} \mathrm{O}(0.15 \mathrm{M})$ and $\mathrm{NaOH}(2.1 \mathrm{M})$ were mixed under continuous stirring. A white precipitate was formed approximately ten minutes after mixing. The complete system was aged overnight at $23{ }^{\circ} \mathrm{C}$ and filtered under vacuum to obtain a clear solution.

The substrates seeded with $\mathrm{ZnO}$ films were placed in a $100 \mathrm{~mL}$ screw-capped glass flask (Normax) and the solution for the growth of $\mathrm{ZnO}$ NRs was added. This glass flask containing the substrate and the solution was placed in an oven at $90{ }^{\circ} \mathrm{C}$ during $1 \mathrm{~h}$. These parameters were selected in order that $\mathrm{ZnO}$ NRs growth occurred in the regime of slow kinetics (23). The substrates covered with ZnO NRs (PET/ $\mathrm{ZnO} \mathrm{NRs}$ ) were then removed from the solution, cleaned with water, ethanol and dried at $60{ }^{\circ} \mathrm{C}$.

\section{Photocatalytic Antibacterial Activity}

The reactor system used to study the photocatalytic efficiency of the synthesized materials in the degradation of bacteria E. coli ATCC 25922 is shown in Figure 1 (a). The light source was an Ultravitalux $300 \mathrm{~W}$ 
(a)

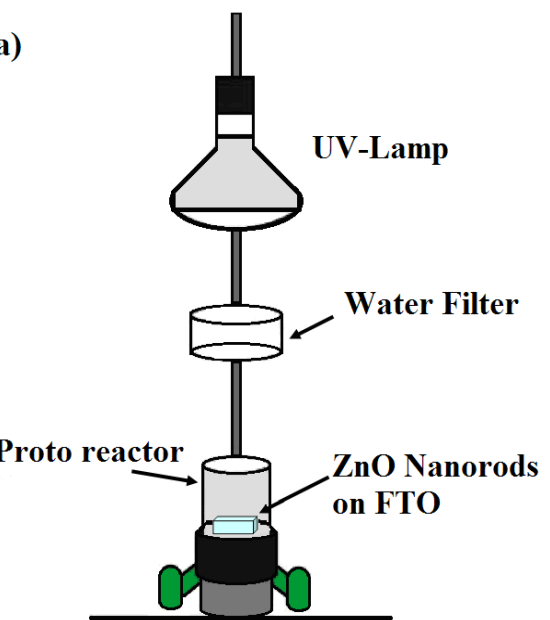

Figure 1. Photocatalytic reactor system for degradation with UV lamp.

OSRAM lamp, placed approximately $30 \mathrm{~cm}$ above the cylindrical photoreactor. The precise lamp to sample distance was set in order to obtain an incident radiation intensity of $30 \mathrm{~W} / \mathrm{m}^{2}$ in the $\mathrm{UV} \mathrm{A} / \mathrm{B}$ range; measured with an UV Light Meter model YK-34 UV.

An aqueous solution with initial volume of $50 \mathrm{~mL}$ was prepared with a bacteria concentration of about $10^{9} \mathrm{CFU} / \mathrm{ml}$ and placed in the photoreactor. Samples of PET/ZnO NRs, $2.0 \times 1.5 \mathrm{~cm}^{2}$, were immersed facing the light, then $1 \mathrm{~mL}$ of solution were collected at different intervals of time (0,30, 60 and 90 minutes). Samples were diluted 1:10 with double distilled water in order to obtain a solution containing CFU in the range: 10-500 CFU/ml. Then $1 \mathrm{ml}$ of the final dilution is taken and vacuum filtered through a sterile filter. This results in all bacteria present in the water being retained on the filter. Finally, the filter was placed onto a paper pad soaked in a liquid growth medium (Membrane lauryl sulphate broth (Oxoid MM0615)) which feeds $E$. coli bacteria, but inhibits the growth of any other bacteria on the filter. Finally the concentration of bacteria was determined by counting, after incubating at $40{ }^{\circ} \mathrm{C}$ during $16 \mathrm{~h}$.

\section{Results and Discussion}

The morphology of films and NRs was studied using scanning electron microscopy (SEM) with an ULTRA-55 field emission SEM (Carl Zeiss SMT AG) working at an electron beam energy of $15 \mathrm{keV}$. Analysis of the rod size distribution was made with the ImageJ software (http://rsb.info.nih.gov/ij/). Figure 2 shows low and high magnification SEM images of a typical $\mathrm{ZnO}$ NRs film growth on SG seeded PET, which surfaces were mechanically roughened. PET surface was completely covered with a well adhered but not uniform $\mathrm{ZnO}$ NRs film. Figure 3 shows high

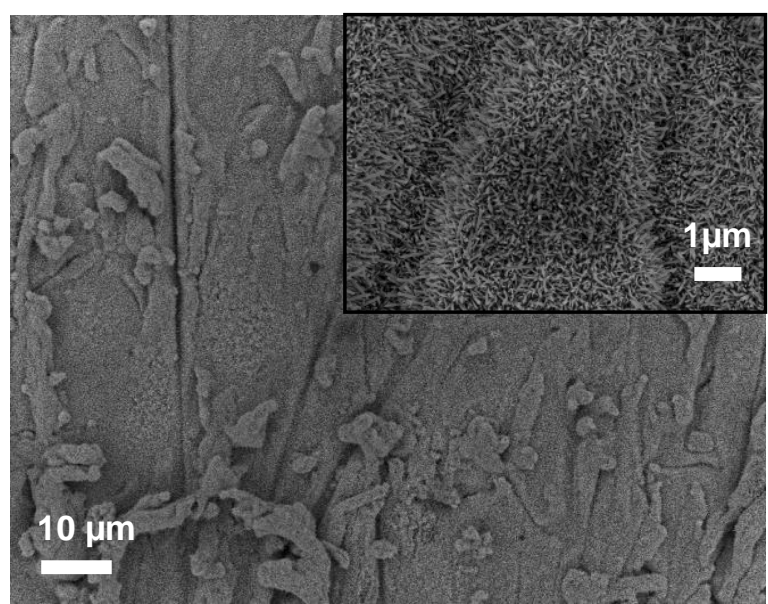

Figure 2. SEM images of a typical $\mathrm{ZnO}$ NRs film synthesized on PET substrates mechanically roughened before seeding with $\mathrm{ZnO}$ sol applied by SG.
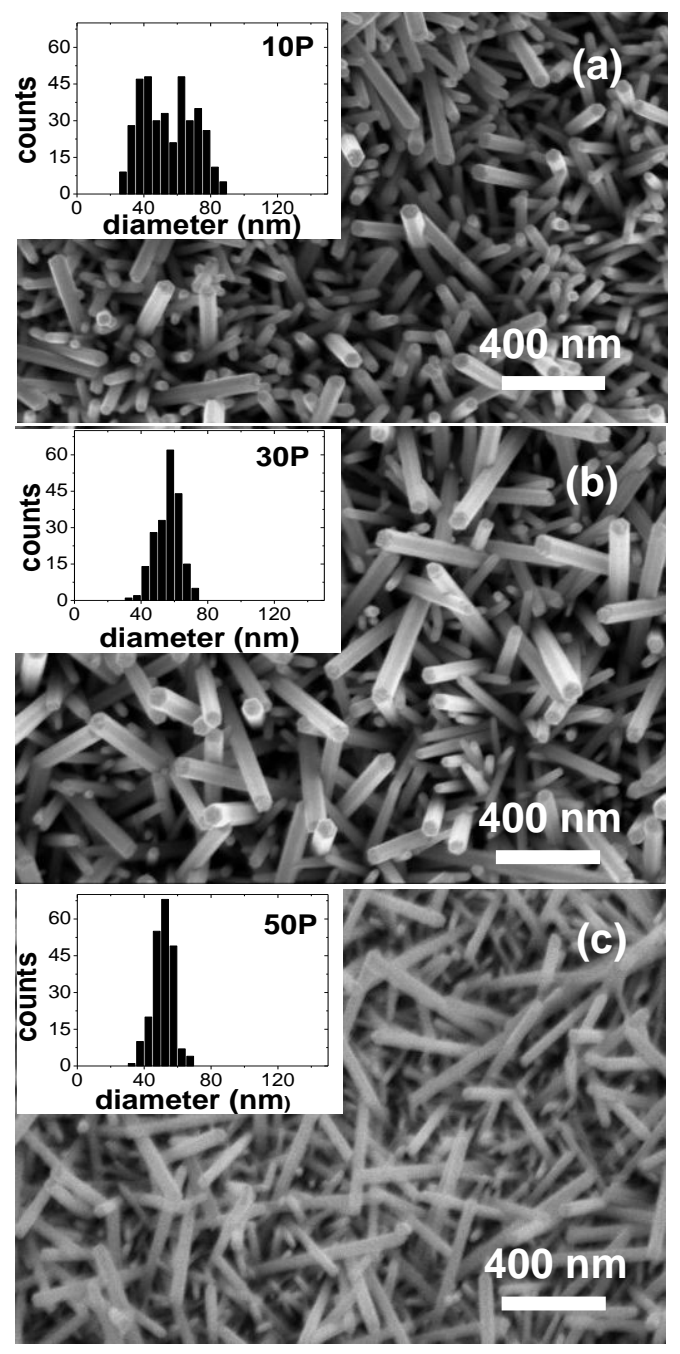

Figure 3. SEM images of ZnO NRs synthesized on mechanically roughened PET substrates seeded with $\mathrm{ZnO}$ sol applied by SG. (a) 10L: 10 layers; (b) 30L: 30 layers; (c) 50L: 50 layers. Insets in each SEM picture show the corresponding distribution of diameters (Sampled over ca.200 NRs from X100,000 SEM micrographs). 


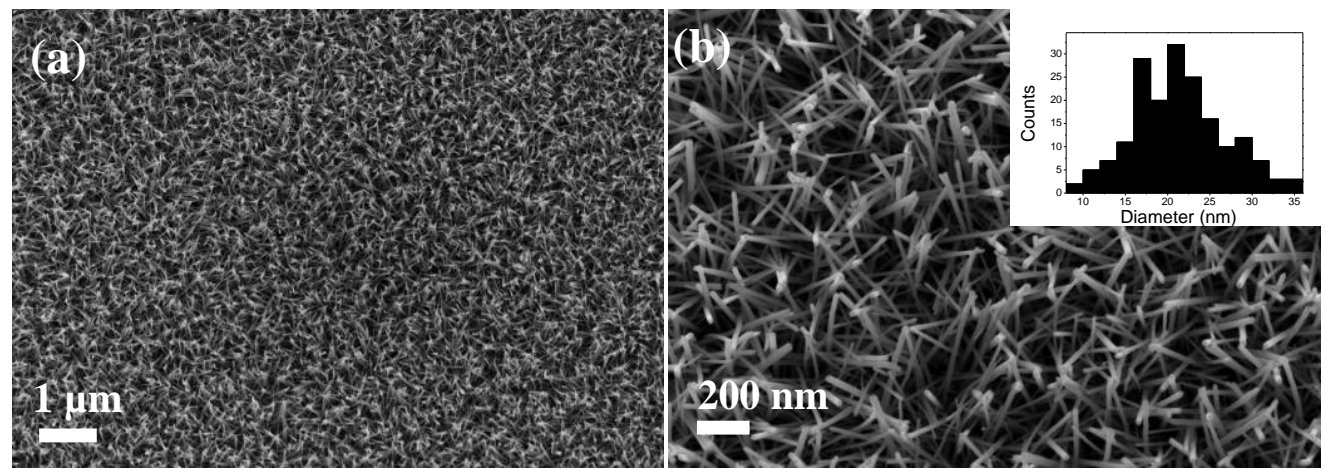

Figure 4. SEM images of ZnO NRs synthesized on chemically roughened PET substrates seeded with ZnO sol applied by dip coating (a) low and (b) high magnification. Insets in (b) show the diameter distribution (Sampled over ca. 200 NRs from X100,000 SEM micrographs). PET substrates were immersed for 2 minutes in $0.25 \mathrm{M}$ ethanol $\mathrm{NaOH}$ solution at $55^{\circ} \mathrm{C}$.
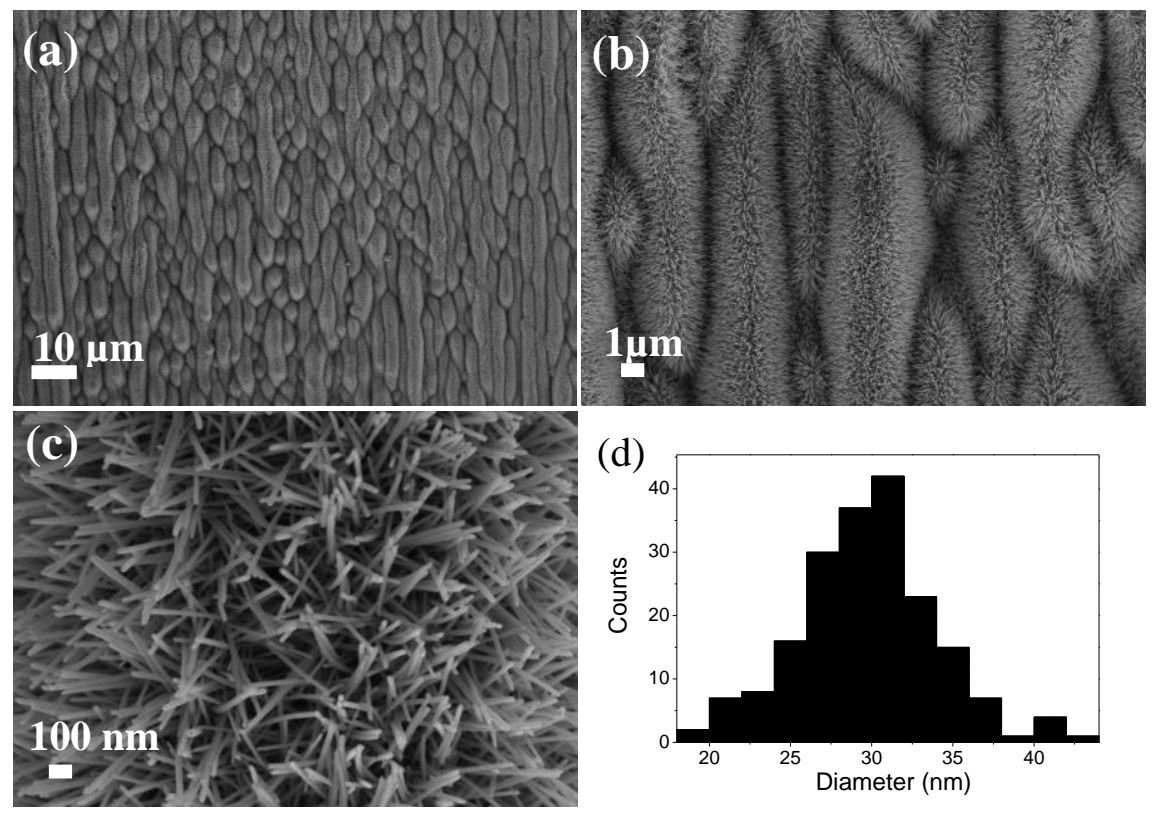

Figure 5. SEM images of ZnO NRs synthesized on chemically roughened PET substrates seeded with ZnO sol applied by dip coating for different magnifications of the same zone (a) $2 \mathrm{kx}$ (b) $10 \mathrm{kx}$, (c) Top side of a like micrometric island. Insets in (b) show the diameter distribution (Sampled over ca.200 NRs from X100,000 SEM micrographs). PET substrates were immersed for 5 minutes in $2.5 \mathrm{M}$ ethanol $\mathrm{NaOH}$ solution at $55^{\circ} \mathrm{C}$.

magnification SEM images of films deposited on PET, seeded by 10,30 or 50 SG layers. In all cases hexagonal $\mathrm{ZnO} \mathrm{NRs}$ were formed, but their growth was in all directions, with poor organization. The diameter and the dispersion of the measured diameters changed with the number of layers of $\mathrm{ZnO}$ seeds. When only 10 layers were deposited on the PET substrate, the diameters of the rods were in the range $30-85 \mathrm{~nm}$. As the number of seeds layers increased the average diameter of the nanorods and the dispersion of diameters size decreased. On the other hand when PET surface was chemically treated the morphology of the $\mathrm{ZnO} \mathrm{NRs}$ films strongly depends on the chemical treatment conditions. Figure 4 shows low and high magnification of $\mathrm{ZnO}$ NRs film growth on a
PET substrate treated in a solution $0.25 \mathrm{M}$ of $\mathrm{NaOH}$ in ethanol at a temperature of $55^{\circ} \mathrm{C}$ for two minutes. PET surface was completely and uniform covered with a $\mathrm{ZnO}$ NRs film with growth in average perpendicularly oriented to the surface. Insets in figure 4 (b) show the diameter distribution, the diameter of the rods were in the range of $10-40 \mathrm{~nm}$. When the chemical treatment was made in a solution $2.5 \mathrm{M}$ of $\mathrm{NaOH}$ in ethanol at a temperature of $55^{\circ} \mathrm{C}$ for five minutes, a textured $\mathrm{ZnO}$ NRs films composed of micrometric islands was obtained as we can see in Figure 5 (a) and (b). Figure 5 (c) shows the top side of a micrometric island where we can see that the NRs are perpendicularly oriented to the surface. Figure 5 (d) shows the diameter distribution of the rods shown in 

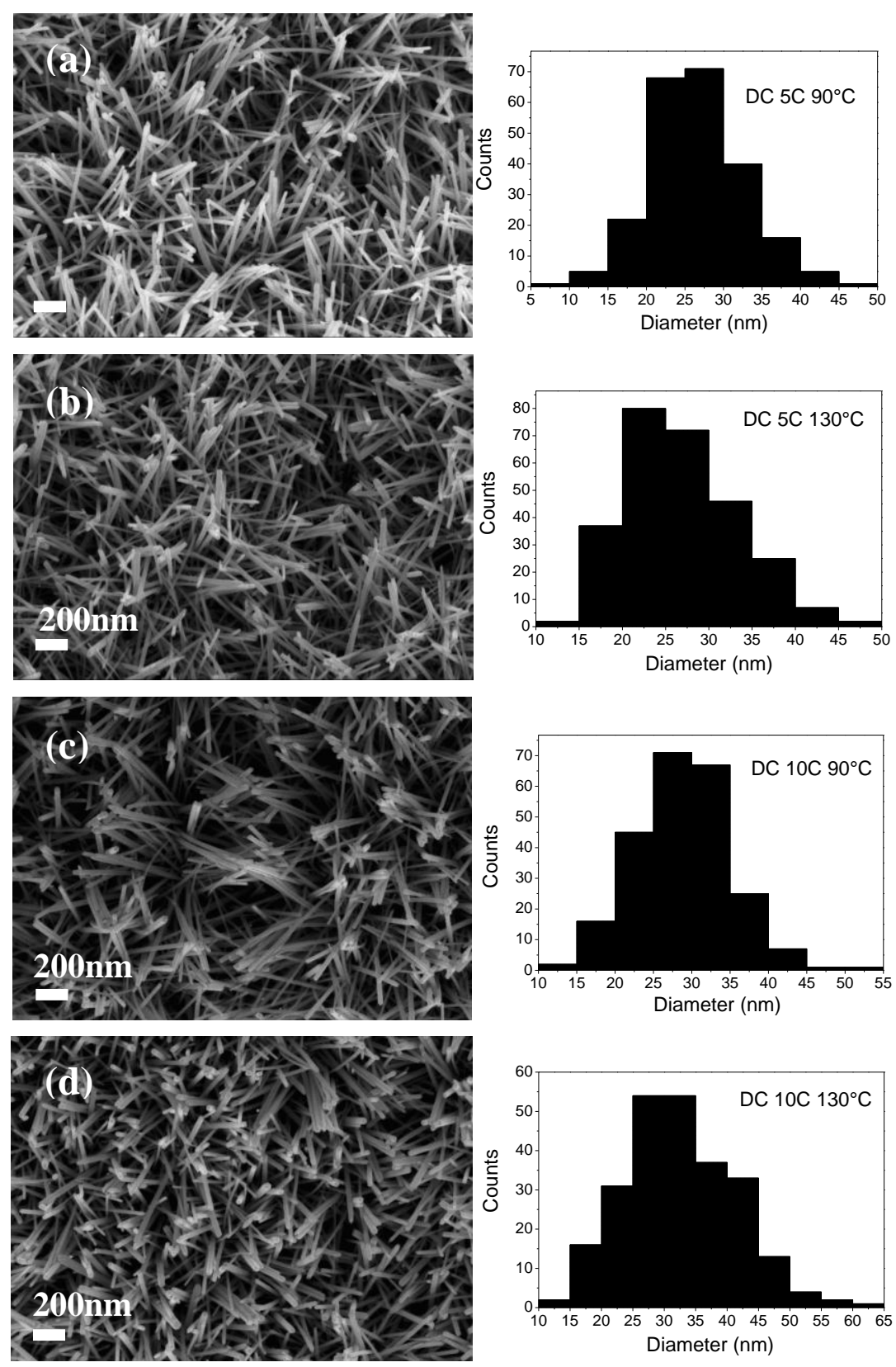

Figure 6. (Left side) SEM images of ZnO NRs prepared under different conditions of seed deposition by dip counting SEM images, (Right side) the corresponding diameter distribution. PET substrates were immersed for 2 minutes in $0.25 \mathrm{M}$ ethanol NaOH solution at $55^{\circ} \mathrm{C}$.

Figure 5(c), diameters of the rods were in the in the range 20-40 nm much thinner than those obtained by mechanically roughened and less dispersed than the NRs obtained with chemical treatment of PET substrate before mentioned. Figure 6 (left side) show SEM images of $\mathrm{ZnO}$ NRs prepared under different conditions of seed deposition by dip counting. In all cases PET substrates were treated in a solution $0.25 \mathrm{M}$ of $\mathrm{NaOH}$ in ethanol at a temperature of $55^{\circ} \mathrm{C}$ for five minutes before dip coating seeding. SEM images corresponds to: (a) 5 layers and a thermal treatment at $90{ }^{\circ} \mathrm{C}$ after each layer deposition (DC $5 \mathrm{C} 90{ }^{\circ} \mathrm{C}$ ), (b) 5 layers and a thermal treatment at $130{ }^{\circ} \mathrm{C}$ after each layer deposition (DC $5 \mathrm{C} 130^{\circ} \mathrm{C}$ ), (c) 10 layers and a thermal treatment at $90{ }^{\circ} \mathrm{C}$ after each layer deposition (DC $10 \mathrm{C} 90{ }^{\circ} \mathrm{C}$ ), (d) 10 layers and a thermal treatment at $130{ }^{\circ} \mathrm{C}$ after each layer deposition (DC $10 \mathrm{C} 130{ }^{\circ} \mathrm{C}$ ), left side of figure 6 shows the corresponding diameter distribution. Figure 7 show the mean diameter of $\mathrm{ZnO}$ NRs as function of the four conditions of seed deposition before mentioned in all case the mean diameter is around $27 \mathrm{~nm}$ with similar dispersion. Figure 8 shows the number of rods per unit of area counted on two different magnification set of SEM 


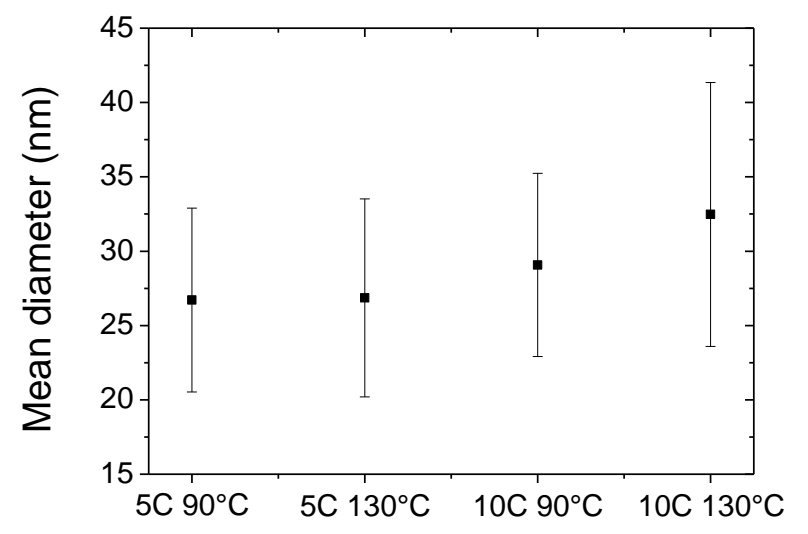

Figure 7. Mean diameter of Nanorods obtained from seeds deposited by dip coating under different conditions.

images. It is observed that for both sets of analysis, 0.32 and $0.82 \mu \mathrm{m}^{2}$, respectively, the NRs density is maximum when seed deposition conditions were 10 layers and a thermal treatment at $130{ }^{\circ} \mathrm{C}$ after each layer deposition (DC $10 \mathrm{C} 130^{\circ} \mathrm{C}$ ).

The crystalline structure of the NRs was determined by X-Ray Diffraction analysis (XRD, Siemens D5000 with $\mathrm{Cu}-\mathrm{K} \alpha$ radiation and a graphite monochromator). Figure 9 shows the results of the XRD analysis of the ZnO NRs films grown on seeds deposited on PET by SG. The diffraction patterns correspond to the hexagonal wurtzite structure of $\mathrm{ZnO}$.

The ZnO NRs synthesized onto a PET substrate were used for the photocatalytic inactivation of $E$. coli bacteria in water. Figure 10 shows the bactericidal activity of two different groups of samples: "SG", where $\mathrm{ZnO}$ NRs were grown on $\mathrm{SG}$ seeded mechanically roughened PET; and "DC", where $\mathrm{ZnO}$ NRs were grown on DC seeded chemically etched PET. In this case etching was produced by immersing the PET substrate in $0.25 \mathrm{M}$ ethanol $\mathrm{NaOH}$ solution at $55{ }^{\circ} \mathrm{C}$ during 2 minutes. Illumination using $30 \mathrm{~W} / \mathrm{m}^{2}$ in the UV-A/B range was selected due to its nil influence in reducing the bacterial population (photolysis plot). Clearly, in the dark (without illumination), there was no influence of the $\mathrm{ZnO}$ nanorods on the viability of bacteria. When the $\mathrm{ZnO}$ NRs films in water were irradiated with the same UV illumination, an effective photocatalytic degradation of bacteria in water was observed. The results indicate that the SG samples displayed lower bactericidal activity than the DC samples. The enhanced bactericidal activity of the DC samples can be a consequence of the lower (averaged) diameter of the ZnO NRs when compared with the SG samples (compare insets of figure 3 with the left side of figure 6). The radii of the $\mathrm{ZnO}$ NRs in the SG samples are approximately double than those in the DC samples. Consequently the active

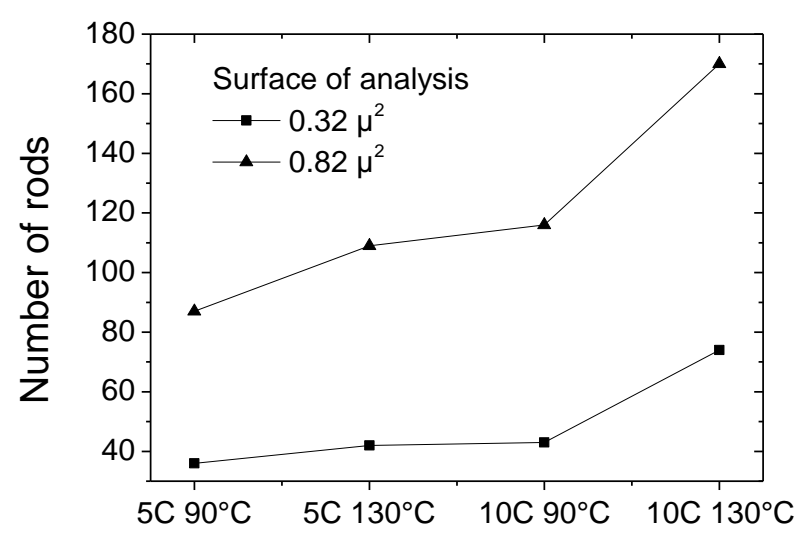

Figure 8. Nanorods surface density obtained from seeds deposited by dip coating.

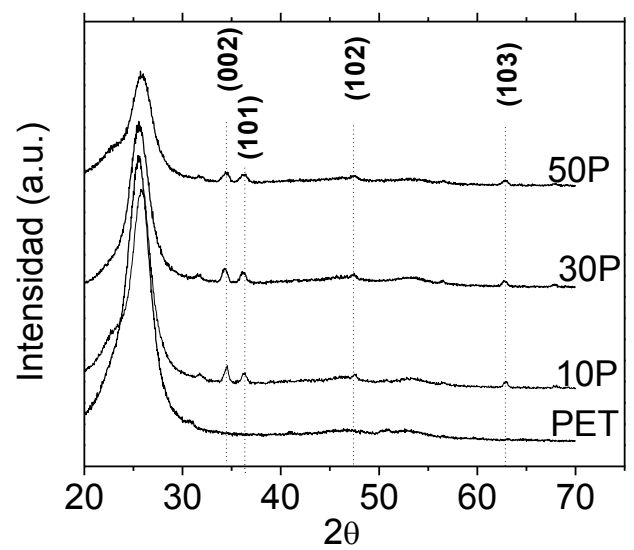

Figure 9. DRX patterns of $\mathrm{ZnO}$ NRs growth on PET substrates seeded with different number of layers of $\mathrm{ZnO}$ sol deposited by SG.

surface exposed to illumination is higher in DC than in SG samples. The highest photocatalytic antibacterial activity was performed by $\mathrm{ZnO} \mathrm{NRs}$ films grown on seeds deposited by dip coating with 10 layers, 5 minutes of chemical treatment of PET surface and a heat treatment at $130{ }^{\circ} \mathrm{C}$ among coatings. With these films the population of viable $E$. Coli dropped more than seven orders, from $3 \times 10^{8}$ to $10^{1} \mathrm{CFU}$. These results correlate well with the NRs samples having higher number or rods per area. This fact is in agreement with the trend observed in figure 8 . This remarkable reduction in viable $E$. Coli indicates that this material is very promising for application in water disinfection, even in water with high concentration of microorganism. Other authors reported total disinfection with powder and supported $\mathrm{ZnO}$, but starting with a much lower concentration of $E$. Coli (see for example $(16,24))$

\section{Conclusions}

ZnO NRs films, with high photocatalytic activities under UV irradiation, were successfully synthesized on polyethylene terphtalate (PET) substrates by a 


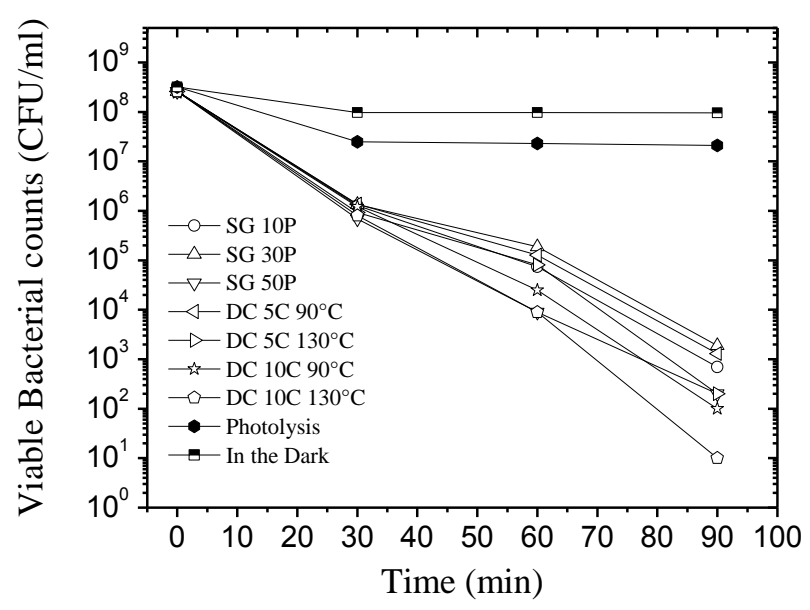

Figure 10. E. coli degradation under UV irradiated $\mathrm{ZnO}$ nanorod films in water. The plot corresponds to the photocatalytic experiments performed with $\mathrm{ZnO}$ NRs growth on PET.

simple two step chemical solution method. We demonstrate that the pre-treatment applied on the PET substrate to increase surface roughness and $\mathrm{ZnO}$ seeds adhesion has a notable influence on the morphology of the $\mathrm{ZnO}$ NRs films. Besides, the seeding procedure also affects the morphology (specially the diameter) of the $\mathrm{ZnO}$ NRs. The results indicate that lower diameters and higher rods density on the surface leads to materials with higher photocatalitycal bactericidal activity for $E$. Coli disinfection. The highest activity was performed by $\mathrm{ZnO} \mathrm{NRs}$ films grown on seeds deposited by Dip coating with 10 layers, 5 minutes of chemical treatment of PET surface and a heat treatment at $130{ }^{\circ} \mathrm{C}$ among coatings. With these films the population of viable $E$. Coli dropped more than seven orders, from $3 \times 10^{8}$ to $10^{1}$ CFU. These results correlates well with the NRs samples having higher number or rods per area. This remarkable reduction in viable E. Coli indicates that this material is very promising for application in water disinfection, even in water with high concentration of microorganism.

\section{Acknowledgements}

This work was supported by the Fincyt Project (Contract $\mathrm{N}^{\circ} 140$-FINCYT-IB-2013), Concytec-4032012 OAJ Project, the Peruvian-Argentinean MINCYT-CONCYTEC PE/11/02 project, ANPCyT PICT-2012-1093. RC, MCM and SG are members of CONICET. The CONICET fellowship granted to LG is acknowledged.

\section{References}

(1) Sondi, B; Salopek-Sondib, B. J. Colloid Interface Sci. 2004, 275, 177-182.

(2) Liu, H.L.; Yang, T.C.K. Process Biochem. 2003, 39, $475-481$.
(3) Alrousan, D.M.A; Dunlop, D.M.A.; McMurray, T.A.; Byrne, J.A. Water Res. 2009, 43, 47-54.

(4) Sunada, K.; Watanabe, T.; Hashimoto, K. J. Photochem. Photobiol. A: Chem. 2003, 156, 227-233.

(5) Skorb, E.V.; Antonouskaya, L.I.; Belyasova, N.A.; Shchukin, D.G.; Mohwald, H.; Sviridov, D.V. Appl. Catal. B: Environ. 2008, 84, 94-99.

(6) Akhavan, O.; Ghaderi, E. Curr. Appl. Phys. 2009, 9, 1381-1385.

(7) Wang, Z. L. Materials Today 2004, 7, 26-33.

(8) Luo, L.; Lv, G.; Li, B.; Hu, X.; Jin L.; Wang, J.; Tang, Y. Thin Solid Films 2010, 518, 5146-5152.

(9) Elias, J.; Tena-Zaera, R.; Lévy-Clément, C. Journal of Electroanalytical Chemistry 2008, 621, 171-177.

(10) Hari, P.; Baumer, M.; Tennyson, W.D.; Bumm, L.A. Journal of Non-Crystalline Solids 2008, 354, 28432848.

(11) Wang, G.; Da, Ch.; Hao, Z.; Jin, Z.; Jinghong, Li. The Journal of Physical Chemistry C 2008, 112, 8850-8855.

(12) Rodríguez, J.; Paraguay-Delgado, F.; López, A.; Alarcón, J.; Estrada, W. Thin Solid Films 2010, 519, 729-735.

(13) Alarcón, J.; Ponce, S.; Paraguay Delgado, F.; Rodriguez, J. Journal of Colloid and Interface Science 2011, 364, 49-55.

(14) Liu, H.L.; Yang, C.K. Process Biochemistry 2003, 39, 475-481.

(15) Jaisai, M.; Baruah, S. Beilstein J. Nanotechnoly 2012, 3, 684-691.

(16) Talebian, N.; Amininezhad, S. M.; Doudi, M. Journal of Photochemistry and Photobiology B: Biology 2013, 120, 66-73.

(17) Ma, S.; Li R.; Lv, Ch.; Xu, W.; Gou, X. Journal of Hazardous Materials 2011, 192, 730-740.

(18) Yi, S.; Choi, S.; Jang, J.; Kim, J.; Jung, W. Journal of Colloid and Interface Science 2007, 313, 705-710.

(19) Yi, S.-H.; Choi, S.-K.; Jang, J.-M.; Kim, J.-A.; Jung, W.-G. Journal of Colloid InterfaceScience 2007, 313, 705.

(20) Luyo, C.; Fábregas, I.; Reyes, L.; Solís, J.L.; Rodríguez, J.; Estrada, W; Candal, R.J. ThinSolid Films 2007, 516, 25.

(21) Medina, A.; Solís, J.L.; Rodríguez, J.; Estrada, W. Solar Energy Materials and SolarCells 2003, 80, 473.

(22) Quintana, M.; Ricra, E.; Rodríguez, J.; Estrada, W. Catalysis Today 2002, 76, 141-148.

(23) Guo, M.; Peng, D.; Shengmin, C. Journal of Solid State Chemistry 2005, 178, 1864-1873.

(24) Baruah, S.; Jaisaia, M.; Dutta, J. Catalysts Science and Technology 2005, 2, 918-921.

Received for review November 6, 2014. Revised manuscript received February 20, 2015. Accepted February 24, 2015. 